\title{
Pharmacist Provided Spirometry Services: A Scoping Review
}

\author{
Alexa Sevin Valentino (ID) \\ Emily Eddy ${ }^{2}$ \\ Zachary Woods ${ }^{3}$ \\ Lori Wilken ${ }^{4}$ \\ 'Pharmacy Practice and Science, The \\ Ohio State University College of \\ Pharmacy, Columbus, OH, USA; \\ ${ }^{2}$ Pharmacy Practice, Ohio Northern \\ University, Ada, OH, USA; ${ }^{3}$ Pharmacy \\ Education and Innovation, The Ohio \\ State University College of Pharmacy, \\ Columbus, OH, USA; ${ }^{4}$ Pharmacy \\ Practice, University of Illinois at Chicago \\ College of Pharmacy, Chicago, IL, USA
}

Correspondence: Alexa Sevin Valentino Pharmacy Practice and Science, The Ohio State University College of Pharmacy, $500 \mathrm{~W}$ 12th Ave, I29B Parks Hall, Columbus, $\mathrm{OH}, 43210$, USA

Tel + | 614292 II86

Email valentino.49@osu.edu
Purpose: Despite international guidelines' recommendations, spirometry is underutilized in the diagnosis and management of asthma and COPD. Spirometry may be an opportunity for trained pharmacists to meet the needs of patients with suspected or diagnosed lung conditions. The aim of this scoping review is to describe the literature including pharmacist provided spirometry services, specifically to identify: 1) the models of pharmacist provided spirometry services, and additional services commonly offered alongside spirometry, 2) pharmacist training and capability to obtain quality results, and (3) pharmacist, physician, and patient perspectives.

Methods: In September 2020, a comprehensive literature search in PubMed and EMBASE was conducted to identify all relevant literature on the topic of pharmacist provided spirometry services using the search term: "pharmacist or pharmacy" and "spirometry or pulmonary function test or lung function test." Literature was screened using inclusion/ exclusion criteria and selected articles were charted and analyzed using the themes above.

Results: A total of 27 records were included. The scoping review found that pharmacist provided spirometry has been conducted around the world in community pharmacies and clinic settings. Community pharmacists may increase access to spirometry screening; the lack of communication with primary care providers and remuneration are barriers that need to be overcome to optimize the utility of the service. Clinic-based services are interprofessional and collaborative, allowing a patient to receive the test, results, diagnosis, and medication changes in one visit. Following comprehensive training, pharmacists felt confident in their ability to perform spirometry and met quality standards at acceptable rates.

Conclusion: Spirometry is an opportunity for pharmacists to improve evidence-based practice for screening and diagnosing lung conditions along with providing comprehensive services to complement testing. Data around provider and patient perspectives is limited and should be further investigated to determine if providers and patients would value and collaborate with pharmacists providing spirometry services.

Keywords: pulmonary function test, community pharmacy, clinical pharmacy services, asthma, chronic obstructive pulmonary disease, COPD, lung disease

\section{Plain Language Summary}

Though recommended by guidelines, spirometry is underutilized in the diagnosis and management of asthma and COPD. The purpose of this scoping review is to describe the evidence around spirometry services provided by pharmacists. We describe the models for service implementation, other services offered in conjunction with spirometry, pharmacist training, the quality of pharmacist provided spirometry, and pharmacist, provider, and patient perspectives. Pharmacist provided spirometry has been studied around the world in community pharmacies and clinic settings. Challenges with payment and lack of communication 
with primary care providers are barriers that were commonly faced in community pharmacy settings, but not in clinic settings. Spirometry was often offered alongside smoking cessation, inhaler education, and medication management services. Spirometry services are an opportunity for pharmacists to expand patient access and improve the quality of care for patients with lung conditions, especially when offered as a package with other clinical pharmacy services.

\section{Introduction}

Chronic Obstructive Pulmonary Disease (COPD) has an estimated global prevalence of $11.7 \%$ and causes around 3 million deaths annually. ${ }^{1}$ COPD is a leading cause of morbidity and mortality worldwide and has far reaching economic and social implications. ${ }^{1}$ The prevalence and burden of COPD are projected to rise over the coming decades. ${ }^{1}$ Asthma has an estimated worldwide prevalence of 262 million and it is estimated that asthma caused 461,000 deaths worldwide in $2019 .^{2}$ Poorly controlled asthma is also associated with socioeconomic burden including higher medical costs, productivity loss, and substantial reductions in quality of life. ${ }^{3}$ Optimal management of these diseases depends on early and accurate diagnosis. $^{1,3}$ Numerous international guidelines recommend spirometry as the gold standard for diagnosis of COPD and asthma. ${ }^{1,3-5}$

Spirometry is the most reproducible and objective measurement of airflow limitation. ${ }^{1}$ It is a noninvasive test that measures the maximal volume of air that an individual can inspire and expire with maximal effort. A spirometry test measures the impact of a disease on lung function, assesses airway responsiveness, and is useful for monitoring disease progression, the effect of therapeutic interventions and determining a prognosis. ${ }^{5}$

Despite widespread recommendations for spirometry, it is often underutilized in the diagnosis and management of COPD and asthma. Lack of spirometry results can lead to underdiagnosis and misdiagnosis, inappropriate treatment, and missed opportunities to alter disease progression. ${ }^{6}$ Across the world, studies have shown that only $18-45 \%$ of patients diagnosed with COPD received a spirometry test at diagnosis and 7-56\% have ever had a spirometry test. ${ }^{6,7}$ Use of spirometry for asthma diagnosis and management is underwhelming, as well. Only $25 \%$ of patients with an asthma diagnosis had evidence of completing spirometry in a study of Canadian primary care practices ${ }^{8}$ and a survey of office-based family physicians and pediatricians in the US demonstrated that only $21 \%$ routinely use spirometry for all guideline recommended clinical situations. ${ }^{9}$

The Global Initiative for Chronic Obstructive Lung Disease (GOLD) calls for all healthcare workers who care for patients with COPD to have access to spirometry. ${ }^{1}$ Global Initiative for Asthma guidelines (GINA) highlight the importance of building the capacity of primary care physicians for asthma diagnosis and management that includes spirometry. ${ }^{3}$ It is known that good quality spirometry is possible in any healthcare setting ${ }^{1}$ and the National Lung Health Education Program recommends that "spirometry for screening and case finding should be available in primary care settings and be used for patients at risk for COPD or asthma". 4 In some countries, efforts are being made to improve the access to spirometry in primary care practices, ${ }^{10}$ but there are still some barriers. The uptake of spirometry in primary care may be limited by primary care providers' familiarity with guidelines, uncertainty regarding usefulness of test results, and lack of training. ${ }^{4}$ A study by Saad et al identified challenges to implementing spirometry in primary care practices, which included the need for health professionals to be trained to provide the service, the lack of time of professionals to provide this service, and the lack of confidence when providers do not have sufficient exposure. Family practices involved in the study concluded that it was best to have a trained professional dedicated to performing spirometry and that this facilitated access to the test. ${ }^{11}$ Other challenges include logistical problems, such as appropriate space within the office to conduct the test and the need for regular calibration of the spirometer. ${ }^{7}$

Cawley et al have previously introduced spirometry as an opportunity for pharmacists to expand patient care services. ${ }^{12}$ Trained pharmacists may be well placed to address some of the barriers to implementing spirometry in primary care practices and could serve to expand access and improve the evidence-based use of spirometry for patients with and at risk of COPD and asthma. Previous reviews of pharmacist provided spirometry services have been conducted, but focused narrowly on the ability of pharmacists to meet quality standards for spirometry ${ }^{13}$ or specifically in the context of COPD services in the community pharmacy setting. ${ }^{14}$ The purpose of this scoping review was to identify and summarize the available evidence around pharmacist provided spirometry services in all settings.

\section{Methods}

This study employed a scoping review methodology, which takes into account all relevant literature, including 
qualitative, quantitative, mixed methods and unpublished literature. ${ }^{15,16}$ Unlike a systematic review, which is conducted to answer a specific research question, a scoping review is conducted to answer broader questions, such as "What is the nature of the evidence around this topic?"15,16 The research team discussed and determined the following inclusion criteria to answer the question posed for this review: "What is known about pharmacist provided spirometry services?" Articles and published conference abstracts were included only when a pharmacist was involved in the provision of the spirometry test or in the interpretation and utilization of spirometry test results. Only articles available in English were included. There was no restriction on publication date because the authors wanted to determine the full volume of research on the topic. One reviewer (AV) conducted a comprehensive literature search in PubMed (in titles and abstracts) and EMBASE (in titles, abstracts, and author keywords) using Boolean logic with the following search term: "pharmacist or pharmacy" and "spirometry or pulmonary function test or lung function test." The initial search was undertaken on September 11, 2020, with location of full text articles and reports for some records identified in the initial search continuing through April 2021. All reviewers also manually searched the references of included articles.

The final search results were imported into Zotero ${ }^{17}$ and duplicates were removed. One reviewer (AV) initially screened all abstracts to determine if they potentially met inclusion criteria and those that did not were removed. All reviewers screened the remaining abstracts and reviewers reached consensus on which articles and abstracts met inclusion criteria for the full text review. All reviewers were assigned a subset of the included articles to review and abstract data from using an initial standardized data abstraction form. Reviewers then met to discuss the findings from the articles and to revise the data abstraction tool. Based on the findings, the data abstraction tool was revised to gather data to answer the following questions: (1) What are the models of pharmacist provided spirometry services and what additional services are commonly offered alongside spirometry? (2) How are pharmacists trained to provide spirometry and what is pharmacists' capability to obtain quality spirometry results? and (3) What are pharmacist, physician, and patient perspectives on pharmacist provided spirometry services? All reviewers used the revised data abstraction tool to abstract data from their assigned articles. A second reviewer was assigned to each article to examine and confirm the data abstracted within the form. As this article was not designed as a systematic review, no papers were excluded on the basis of quality. ${ }^{16}$ The authors describe all of the relevant literature identified and highlight some of the quality limitations of the existing evidence throughout the findings below.

\section{Findings}

As shown in Figure 1, the initial search yielded 154 articles and conference abstracts. After removing duplicates, 111 unique articles and abstracts were reviewed. After screening for inclusion and exclusion criteria, the authors reviewed and analyzed 26 papers (23 original articles, 2 reviews, and 1 commentary) and one conference abstract. Of those, 24 describe pharmacist provided services in community pharmacy settings $(n=16)$ and clinicbased settings $(n=8)$, such as primary care practices, federally qualified health centers, and an internal medicine multi-specialty practice. Additionally, this review includes two review papers and one paper describing a survey of physicians' perspectives on the theoretical involvement of pharmacists in spirometry. Included articles described spirometry services in Australia $(n=9)$, Canada $(n=1)$, Italy $(n=1)$, Spain $(n=2)$, the United Kingdom $(n=3)$, and the United States $(n=8)$. With the international nature of this review, it is important to note that the pharmacy practice scope, payment opportunities, relationships with providers (including physicians, nurse practitioners, and physician assistants), and public perception of pharmacists may vary from country to country. Table 1 describes country, setting, characteristics of spirometry services and additional services provided by the pharmacist.

\section{Community Pharmacy Models}

A total of 16 papers and reports describing spirometry services in community pharmacy settings were included in this review. ${ }^{18-33}$ Most community pharmacy spirometry services were pre-bronchodilator tests for screening purposes to identify patients at high risk of COPD, ${ }^{18,23,24,26-29,32}$ obstructive lung conditions, ${ }^{22,31}$ or poor asthma outcomes ${ }^{20}(n=11)$. Additionally, a group of studies conducted in Australia described and assessed implementation of spirometry services for the purposes of asthma management in the community pharmacy setting $(\mathrm{n}=5) \cdot{ }^{19,21,25,30,33}$

In community pharmacies, the spirometry service was often incorporated into the normal workflow of the pharmacy. ${ }^{18,23-25,29,30}$ Additionally, some studies describe other models, such as special booths, screening days or 


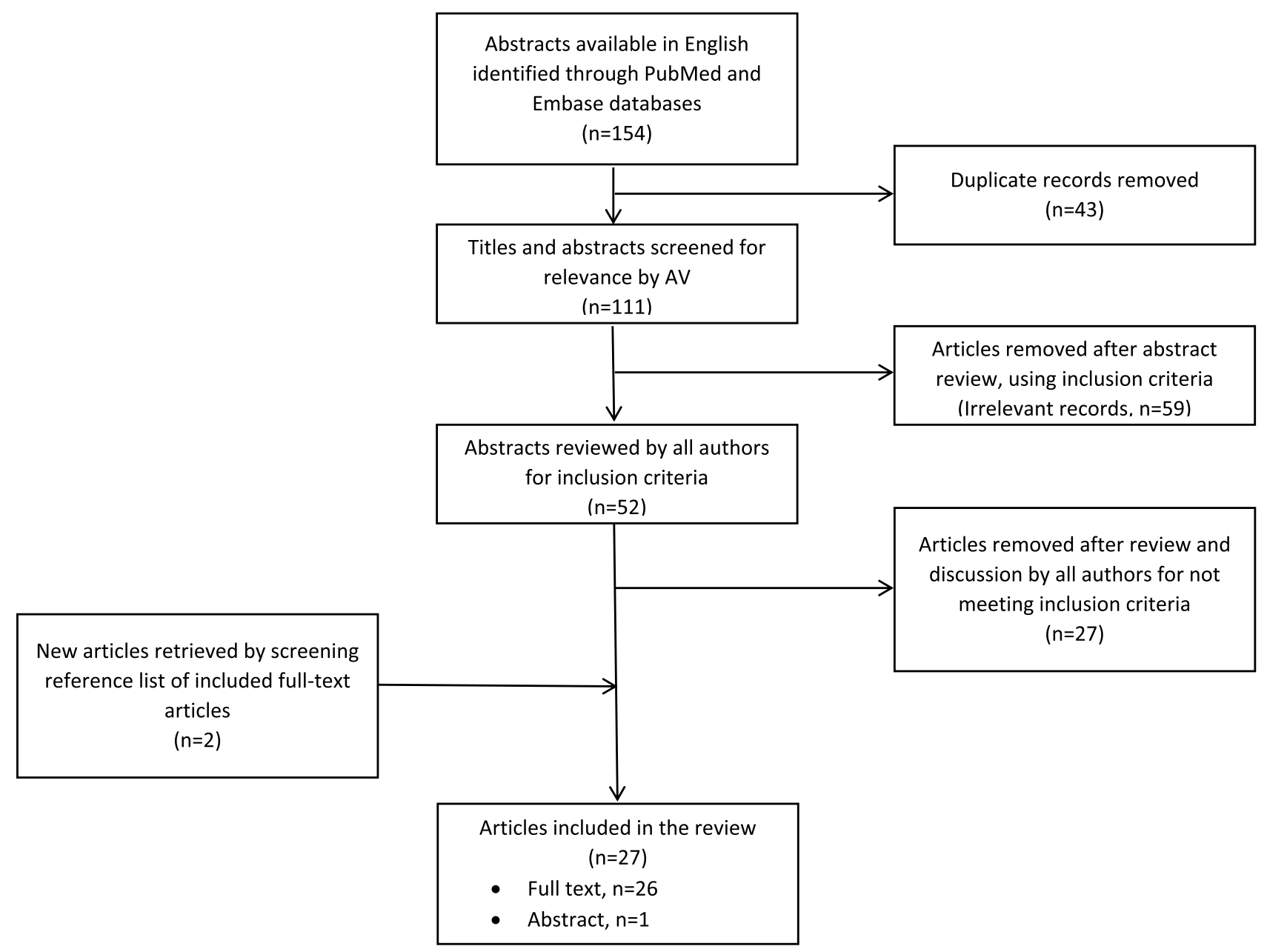

Figure I Flow diagram of the search and selection process used for a literature search for articles on pharmacist-provided spirometry services for a scoping review.

appointment-based models within the pharmacy ${ }^{18,25,27,29}$ or community pharmacists participating in community health fairs or health screening events at corporate offices. $^{28}$ Several studies required that participating pharmacies have a private area where the pharmacist could meet with the patient to perform the test ${ }^{20,24-26,30} \quad(n=5)$ and that at least two pharmacists were on duty at all times $(n=4) .{ }^{19,20,25,29}$ Where it was not required, there was a trend of higher screening rates when a second pharmacist or an intern was on duty. ${ }^{26}$

Most often patients were recruited for the spirometry service by convenience from customers entering the pharmacy, ${ }^{28,31}$ though specific customers were typically targeted, usually because they were filling prescriptions for respiratory drugs, purchasing cough medications or smoking cessation products, or endorsed respiratory symptoms or smoking $(n=12) .{ }^{18-20,22-26,30,32}$ Patients were also recruited through advertisements in the newspaper and flyers or posters in the pharmacy. ${ }^{18,22,28,30}$
For those community pharmacy programs offering a screening service, a screening questionnaire was typically utilized to identify patients' level of risk for COPD. These questionnaires were either used to identify patients who were eligible to receive the spirometry test ${ }^{18,23,24,29}$ or were reviewed in addition to the spirometry test results for a comprehensive risk assessment. ${ }^{26,28,32}$ The eligibility criteria used in these screening programs varied widely. See Table 2 for eligibility criteria and screening questionnaires used in COPD case-finding studies. It is important to note that screening recommendations for COPD have changed over time. There is also some disagreement between expert guidelines and recommendations vary by geographic location. The GOLD Guidelines recommend spirometry for any patient over age 40 with symptoms and/or risk factors consistent with COPD, ${ }^{1}$ while the US Preventive Services Task Force recommends against screening for COPD for any patient without symptoms. ${ }^{34}$ While studies varied in their consistency with these 


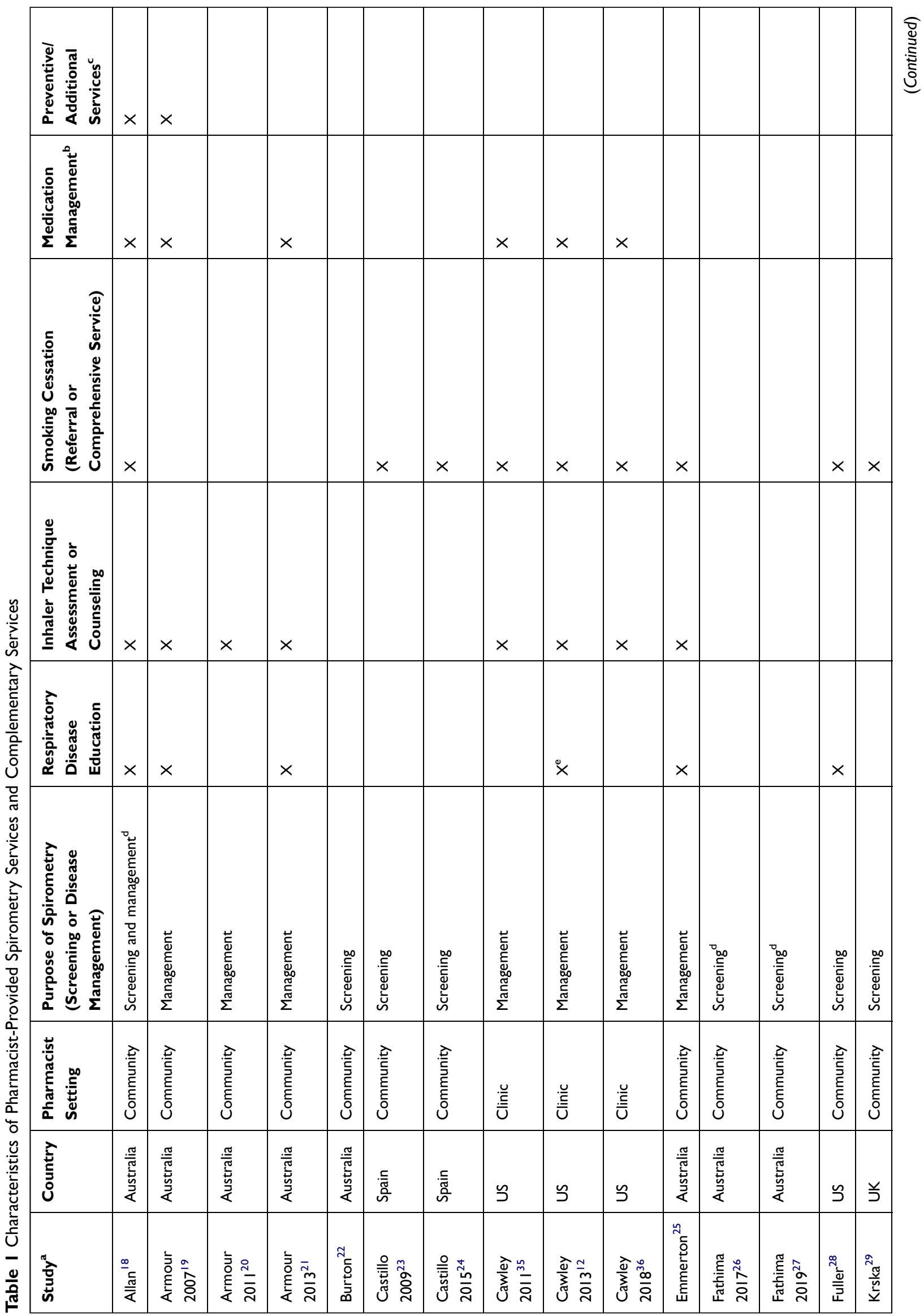




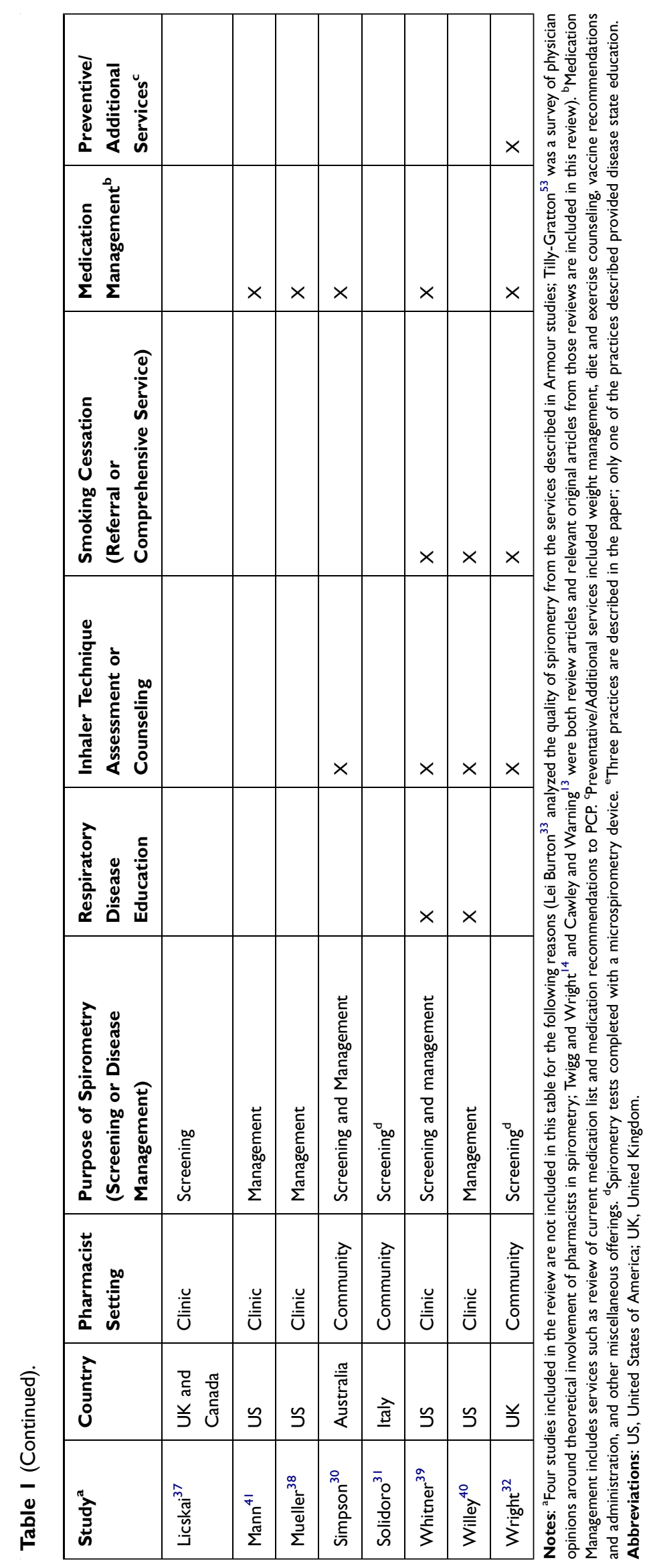




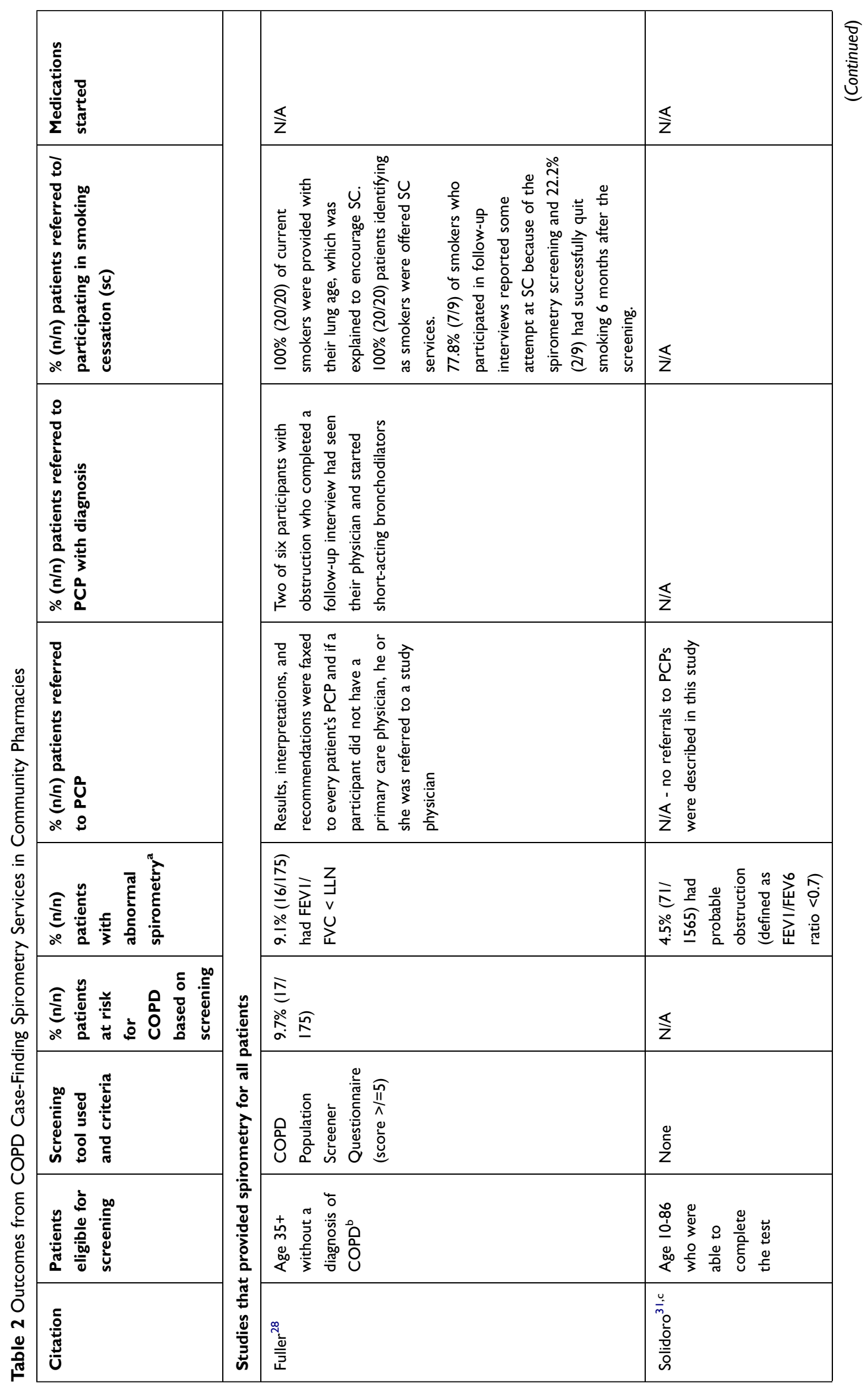




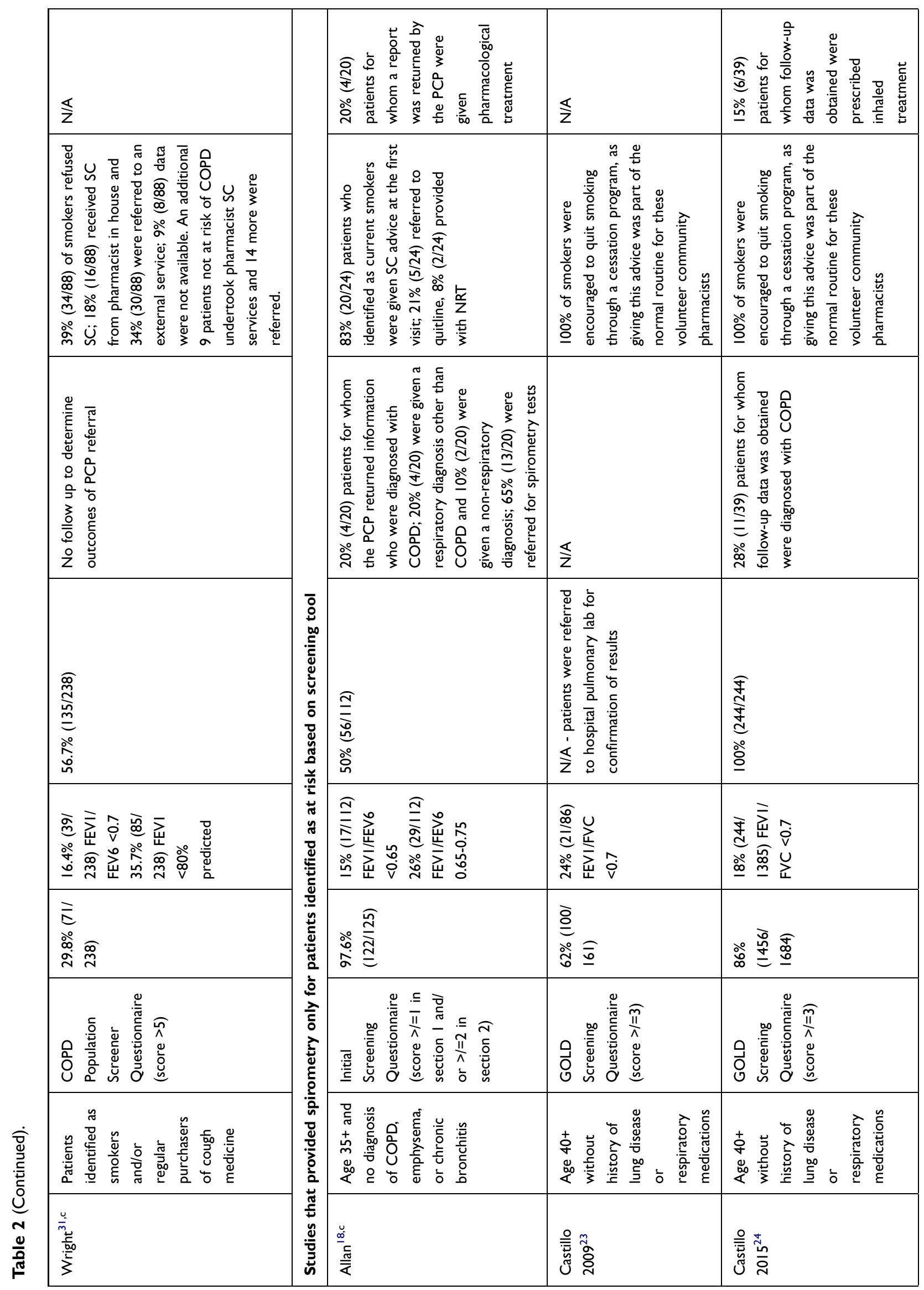




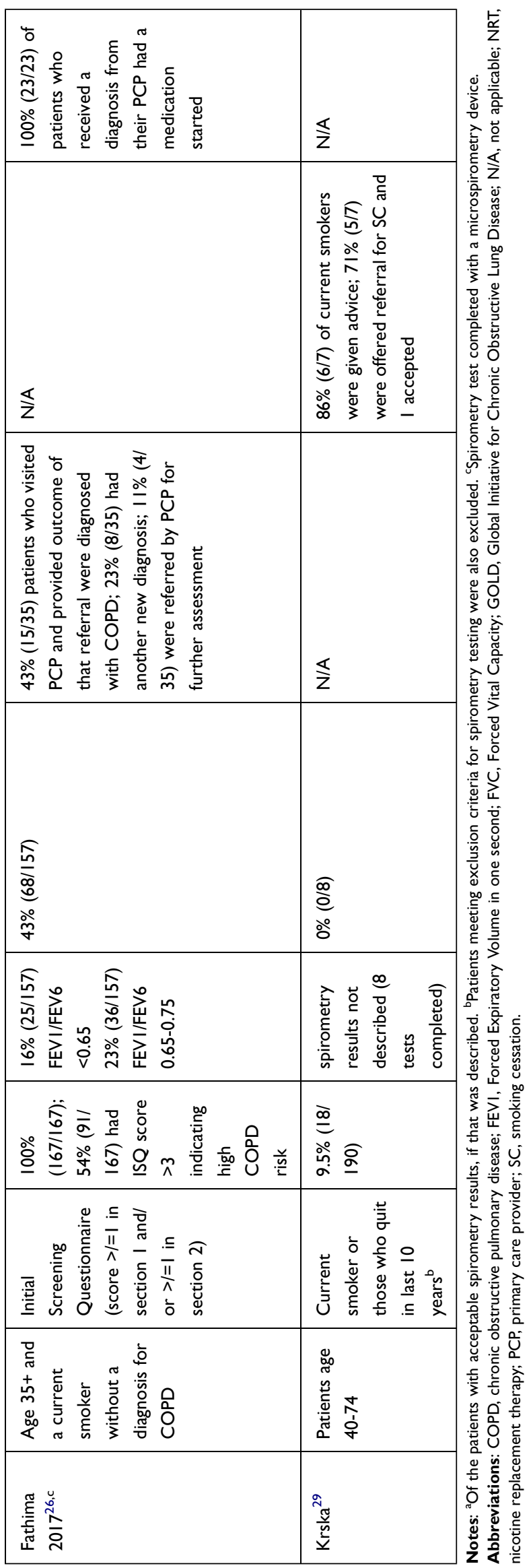


guidelines, they did demonstrate an opportunity for pharmacists to be involved in identifying patients at risk of obstructive lung disease.

A major challenge that community pharmacists faced was communicating with patients' primary care providers (PCPs) to provide screening results and recommendations for diagnostic spirometry. In some studies, pharmacists attempted to send recommendations directly to PCPs, while other services required patients to take recommendations back to their PCP. Castillo et al noted that the lack of communication between the PCPs and community pharmacists was a weakness in their study; of 244 patients referred to their PCPs for abnormal results, pharmacists received a communication back from the PCP for only $39 .^{24}$ Similarly low response rates from PCPs were found in other studies, as well. ${ }^{18,26}$

Reported outcomes related to pharmacist-provided spirometry services varied across studies, though many reported on quality, as we describe below. For the subset of studies related to a COPD case-finding spirometry service in a community pharmacy setting, common outcome measures were related to patients' COPD risk, abnormal spirometry results, referrals and recommendations to PCPs and the outcomes of those pharmacist actions. ${ }^{18,23,24,26,28,29,31,32}$ (Table 2) The primary goal of a COPD screening service is to identify patients with the condition, and unfortunately, the response rates for determining patient diagnoses were low across studies. While identifying patients at risk of COPD and referring them to primary care are important intermediary steps, it is difficult to determine the ultimate impact on the outcome of interest, which is COPD diagnosis and proper management. Future studies should address this issue. Health information technology and interoperable electronic medical records may help to facilitate this communication between PCPs and community pharmacists and may be an intervention worth assessing in future research.

Several papers from the community pharmacy setting did not specifically address reimbursement for the spirometry service $(n=3) .{ }^{23,26,30}$ For those that did describe it, most often payment was associated with participation in the research study and the funding came from government agencies or drug manufacturers $(n=5) \cdot{ }^{18,19,21,25,28}$ In one study, patient participants paid $\$ 10$ plus tax to receive the spirometry service. ${ }^{22}$ In a study in Italy, pharmacists received payments for the spirometry screening service through their National Health Service. ${ }^{31}$ Another study in the UK evaluated potential cost savings to the National
Health Service for the spirometry and smoking cessation service. ${ }^{32}$ Pharmacists did not receive any incentives or remuneration in some studies, thus the spirometry service was provided to patients at no cost and the costs of the service were subsidized by the pharmacy $(n=2) .{ }^{24,29}$ The service offerings varied across studies, but pharmacists in the study by Allan et al reported that initial and follow-up visits averaged 31 and 15 minutes, respectively, with an additional 28 minutes for paperwork. ${ }^{18}$

Many authors concluded that trained community pharmacists could effectively perform spirometry services for the purposes of COPD case-finding $(n=7){ }^{18,23,24,26,28,31,32}$ Authors also identified that some challenges would need to be addressed for the service to be optimized and sustainable in community pharmacies. ${ }^{18,26,27,29}$ In one study of pharmacist experiences with a COPD case-finding service, $74 \%$ of pharmacists reported that they were likely or very likely to continue providing the service beyond the research study and $89 \%$ indicated that they would charge a fee between $\$ 5-40$ to patients. ${ }^{27}$ However, most articles describing services in the community pharmacy setting did not mention plans for continuation of the service beyond the study period. Another review identified that community pharmacist motivation for providing spirometry screening services is not well established and that this would need to be addressed for successful broad scale implementation. ${ }^{14}$ While pharmacists in the community setting may increase access to screening services for patients, the logistical challenges, communication deficiencies with PCPs, and lack of remuneration for spirometry in this setting are barriers that have likely prevented wide-scale implementation.

\section{Clinic-Based Models}

Pharmacist provided spirometry services in outpatient, primary care practices ${ }^{12,35-40}$ and a multispecialty medical group practice ${ }^{41}$ have also been described $(n=8)$. In these settings, spirometry services are more commonly offered for both screening and disease management. ${ }^{35,36,38,40}$ Models for pharmacist provided spirometry in clinic settings varied, though most utilized an appointment-based model $(\mathrm{n}=5) \cdot{ }^{35,36,38,39,41}$ Some clinics offered dedicated days for the spirometry service $e^{35-37}$ while others included spirometry in the mix of services offered by the pharmacists. ${ }^{12,38}$ In the medical practice setting, identifying patients for spirometry services is quite different from the community pharmacy setting. Some studies describe proactive pharmacist identification of patients that may be 
eligible using information from the electronic medical record (EMR), ${ }^{39,41}$ while others describe primary care provider referrals as the major driver of patient recruitment. ${ }^{35,38}$ In the studies that included pharmacist recommendations for spirometry testing, PCP acceptance rates varied from $47 \%$ in a COPD case-finding and caseconfirming approach ${ }^{39}$ to $75 \%$ for patients already diagnosed with COPD. ${ }^{41}$ PCPs' choice of guidelines may impact acceptance rates and they may be less likely to accept recommendations for spirometry for asymptomatic patients without a current respiratory diagnosis.

In the outpatient clinic setting, the typical pharmacistprovided spirometry service included: the spirometry test, an assessment of pulmonary symptoms, medication use, and the results of the spirometry test, medication recommendations, and patient education on the proper use of respiratory devices. ${ }^{35,36,39-41}$ These visits were scheduled for 60-90 minutes ${ }^{12,35}$ and often included interprofessional collaboration during the visit. ${ }^{35,36,39,41}$ Access to the electronic medical record (EMR) is an important component of spirometry services in this setting. In addition to identifying patients, the EMR was utilized to communicate recommendations to providers and to document spirometry results, patient symptoms, and pharmacist assessments and recommendations. ${ }^{35,38,39,41}$

One major difference between the screening services described in community pharmacy settings and the diagnostic spirometry tests provided in clinic settings was the inclusion of a post-bronchodilator test. ${ }^{35,36}$ This certainly adds to the length of the visit, as the visit includes administration of the bronchodilator and a waiting period before the post-bronchodilator maneuvers can be performed. For patients who are identified as at risk for obstructive lung conditions, having a diagnostic spirometry test (rather than a screening) saves a step in the process and could result in a patient receiving evidence-based therapies sooner.

Among the studies in clinic settings, Cawley and Warning and Whitner et al included the results of pharmacist provided spirometry tests. In Cawley and Warning, among patients that were able to complete the test to satisfactory standards, $52 \%$ had abnormal results and pharmacists aided in identifying reversible airway disease, COPD, restrictive defects, and mixed obstructive/restrictive defects. ${ }^{36}$ Whitner et al describe correcting inappropriate or misdiagnosis of COPD, new COPD diagnosis, and confirmation of existing COPD diagnosis. ${ }^{39}$ The interprofessional, collaborative nature of the spirometry services in clinic-based settings allows for immediate diagnosis by the PCP. With a spirometricallyconfirmed diagnosis, pharmacists can go on to make guideline-driven recommendations for pharmacotherapy all in the same visit with the patient.

In most cases, remuneration for pharmacist services in clinic settings were not addressed, however, two papers described the average reimbursement for a spirometry visit as $\$ 101.12^{38}$ and $\$ 144.43 \pm 36.34,{ }^{40}$ which may include the additional medication management services provided. Cawley and Warning specifically call for pharmacists to become familiar with procedural codes for billing spirometry services and suggests pharmacists work with their clinic's reimbursement specialists. ${ }^{35}$ The sustainability of spirometry services in these settings is evidenced by the longevity of the programs ${ }^{36,39}$ and expansion of the service to additional clinic sites. ${ }^{39}$ Pharmacist consult agreements are cited as an opportunity for further expansion of spirometry services. ${ }^{36,39}$

Clinic-based spirometry services provided by pharmacists may increase patient access to testing and PCP access to results. Whitner et al found that among patients eligible for spirometry testing based on GOLD guideline criteria for age and smoking status, spirometry was ordered significantly more when a pharmacist proactively recommended the test as compared to usual care (47.2\% vs $7.7 \%, \mathrm{P}<0.001)$. This resulted in significantly more eligible patients completing a spirometry test $(23.2 \%$ vs $3.1 \%, \mathrm{P}<0.001) .{ }^{39}$ Just the existence of a pharmacist providing spirometry services in their clinic may increase provider referrals. Mueller et al found a significant difference in the percent of all patients with a spirometry referral $(1.13 \%$ and $0.59 \%$, respectively, $\mathrm{P}<0.0001)$ and the percent of all patients with spirometry results $(0.55 \%$ and $0.27 \%$, respectively, $\mathrm{P}=0.0002$ ) between sites with and without the pharmacist service. Mueller et al also demonstrated a significantly higher completion rate for spirometry when referred to the pharmacist service compared to external pulmonary function testing facilities (70.0\% and $40.9 \%$, respectively, $\mathrm{P}=0.0004)$. These results indicate that patients may be more likely to complete spirometry when it is conveniently located in the primary care provider's office, ${ }^{38}$ a finding that was also supported by the experiences of pharmacist-managed spirometry in primary care in Minnesota. ${ }^{12}$ Prospective studies specifically designed to assess the impact of pharmacist-provided services on patient access to spirometry could provide further evidence to support these findings. 
Several authors highlight the pharmacist as uniquely positioned to provide spirometry services within clinic settings because of the value-added services they can provide including gathering patient history, assessing spirometry results and medication lists, making guideline-driven medication recommendations, and assessing and educating patients on proper inhaler technique. ${ }^{12,35,38,39}$ Mueller et al and Mann and Zaiken both concluded that a pharmacistprovided spirometry service within the clinic may increase patient access through increasing referrals for and completion of spirometry tests. ${ }^{38,41}$ Similar to the studies conducted in community pharmacy settings, these studies identified that existing relationships between the primary care providers and pharmacists led to higher referral rates and recommendation acceptance rates. ${ }^{38,41}$ Spirometry may be an area of future growth for sustainable, clinic-based pharmacist services. Spirometry testing provides an opportunity for pharmacists to improve evidence-based practice for screening and diagnosis of lung conditions and can provide a pipeline of patients for chronic disease management services under consult agreements.

\section{Pharmacist Training and Ongoing Support} The American Thoracic Society (ATS) and European Respiratory Society (ERS) Standardization of Spirometry 2019 Update highlights a motivated and trained operator as a key element for obtaining high quality spirometry test results. ${ }^{5}$ The 2019 ATS/ESR guidelines do not endorse any specific training program for spirometry but acknowledge that there are many training programs available and that short term follow-up and supplementary training are integral to maintaining spirometry quality. ${ }^{5}$ For studies included in this review, initial training for pharmacists varied in the modality, length, accreditation, content, and instructors. Most studies report training pharmacists in person through workshops $(\mathrm{n}=10) .{ }^{19-21,23-25,28,30,37,41}$ Some studies describe online training modules ${ }^{27}$ or a mixture of online and in person training. ${ }^{18,26}$ Examples of training content included: disease state pathophysiology and overview (asthma or COPD), spirometry device use, spirometry interpretation, and study protocol. The length of training varied from a couple hours to 4-day (16 hour) workshops. Only one of the studies described having a training program that was accredited, ${ }^{24}$ and several others noted that their training materials were based on the ATS/ERS quality guidelines or National Institute for Occupational Safety and Health (NIOSH) training material. ${ }^{19,23,36,37}$ One study noted that training was provided by the National Respiratory Training Center (NRTC). ${ }^{41}$ Five of the studies reference a cumulative examination after training, in which pharmacists had to demonstrate mastery. ${ }^{21,24-26}$

Ongoing support, after the initial training, to pharmacists who were providing spirometry services varied greatly in the described studies. Support in some studies consisted of follow-up phone calls to the pharmacists but mainly consisted of patient recruitment and study protocol support. ${ }^{25-27}$ Other support offered to pharmacists providing spirometry included ongoing access to specialists through telephone ${ }^{19,22,37}$ and in person visits by respiratory specialists ${ }^{22}$ or nurses. ${ }^{29}$ Some pharmacists had support in the interpretation of results from physicians/ pulmonologist, ${ }^{35,36}$ physician assistants, ${ }^{41}$ and respiratory specialists. ${ }^{13,22}$ The utility of providing ongoing support to the pharmacists was not evident in the reviewed studies. One group of studies mentioned follow-up phone calls from investigators as helping with patient recruitment ${ }^{26,27}$ and another mentioned that support was helpful but did not provide specifics. ${ }^{29}$

Further description and evaluation of the spirometry training provided to pharmacists would be useful to identify programs that demonstrate outcomes that balance the cost and time commitment involved. Future work to evaluate currently available training programs and their effect on the quality of spirometry would be a helpful addition to the literature. For a practitioner desiring to receive training there are a variety of training programs available internationally including: the HERMES spirometry training program developed for practitioners across Europe, ${ }^{42}$ the Australian and New Zealand Society of Respiratory Science spirometry training program, ${ }^{43}$ the American Lung Association practitioner training program, ${ }^{44}$ and the NIOSH spirometry training program. ${ }^{45}$

\section{Quality}

To determine the utility of pharmacist provided spirometry services, it is important to establish that pharmacists can conduct spirometry tests that meet established criteria for quality. The quality of spirometry is generally determined by the accuracy and reproducibility of the spirometry test. There have been several important guidelines that have been largely accepted in rating the quality of spirometry tests, ${ }^{46,47}$ with the most recent update in 2019 providing a grading system $(\mathrm{A}, \mathrm{B}, \mathrm{C}, \mathrm{D}, \mathrm{E}, \mathrm{U}, \mathrm{F})$ to assess the quality of the test. ${ }^{5}$ The grading system should help in the interpretation of the results and with the 
probability that the same result would happen if the test was attempted again. Practitioners should aim for "A" quality, but in cases where that is not possible the results may still be useful. ${ }^{5}$
Ten of the articles in this review included some information about the quality of the spirometry provided by pharmacists. ${ }^{19,20,22-24,28,33,35-37}$ Table 3 describes the devices, quality criteria and results from these articles. It

Table 3 Quality of Pharmacist Provided Spirometry Tests

\begin{tabular}{|c|c|c|c|}
\hline Study & Spirometry Device Used & Spirometry Quality Measures & Quality Data \\
\hline \multicolumn{4}{|c|}{1994 ATS Guidelines ${ }^{46}$} \\
\hline Burton $^{22}$ & SpiroCard $®$ Device $^{\text {a }}$ & $\begin{array}{l}\text { I994 ATS criteria of acceptability and } \\
\text { reproducibility }\end{array}$ & $\begin{array}{l}66 \% \text { met all three acceptability criteria; of the } \\
\text { tests meeting acceptability criteria, } 86 \% \text { also met } \\
\text { reproducibility criteria for } F E V_{\text {, and FVC }}\end{array}$ \\
\hline Cawley ${ }^{35}$ & $\begin{array}{l}\text { CardioPerfect } \circledR \text { Workstation } \\
\text { and SpiroPerfect } \AA^{\mathrm{b}}\end{array}$ & $\begin{array}{l}\text { I994 ATS guidelines of FVC or FEV, with } \\
\text { in } 0.2 \mathrm{~L} \text { of } 200 \mathrm{~mL} \text { of the next largest value }\end{array}$ & $75 \%$ met quality standard \\
\hline \multicolumn{4}{|c|}{1994 ATS Guidelines ${ }^{46}$ and 2005 ATS/ERS Guidelines ${ }^{47}$} \\
\hline Licskai $^{37}$ & $\begin{array}{l}\text { Jaeger Masterscope }{ }^{c} \\
\text { Spirometer }\end{array}$ & $\begin{array}{l}\text { Both ATS } 1994 \text { and ATS/ERS } 2005 \text { quality } \\
\text { criteria were used in analysis of quality } \\
\text { (criteria changed in the middle of the } \\
\text { study) }\end{array}$ & $\begin{array}{l}76.5 \% \text { met ATS I } 994 \text { criteria for both } \\
\text { acceptability and reproducibility } \\
71.4 \% \text { met the ATS/ERS } 2005 \text { criteria for both } \\
\text { acceptability and reproducibility }\end{array}$ \\
\hline \multicolumn{4}{|c|}{2005 ATS/ERS Guidelines ${ }^{47}$} \\
\hline $\begin{array}{l}\text { Armour } \\
2007^{19}\end{array}$ & EasyOne ${ }^{\circledR}$ Device $^{d}$ & $\begin{array}{l}\text { Spirometer device grading system A-D, F; } \\
\text { that corresponds to } 2005 \text { ATS/ERS quality } \\
\text { standards }\end{array}$ & $85 \%$ met $A, B$, or $C$ criteria \\
\hline Armour $2011^{20}$ & EasyOne ${ }^{\circledR}$ Device $^{d}$ & $\begin{array}{l}\text { Spirometer device grading system (A-D, } \\
\text { F), that corresponds to } 2005 \text { ATS/ERS } \\
\text { quality standards }\end{array}$ & $81 \%$ met $A, B$, or $C$ criteria \\
\hline Castillo $2009^{23}$ & EasyOne ${ }^{\circledR}$ Device $^{\mathrm{d}}$ & $\begin{array}{l}\text { Spirometer device grading system (A-D, } \\
\text { F), that corresponds to } 2005 \text { ATS/ERS } \\
\text { quality standards }\end{array}$ & $\begin{array}{l}70 \% \text { met A or B criteria; } \\
73 \% \text { considered "good" by the expert }\end{array}$ \\
\hline Castillo $2015^{24}$ & EasyOne ${ }^{\circledR}$ Device $^{d}$ & $\begin{array}{l}\text { Spirometer device grading system (A-D, } \\
\text { F), that corresponds to } 2005 \text { ATS/ERS } \\
\text { quality standards }\end{array}$ & $\begin{array}{l}75.1 \% \text { met } A, B \text { or } C \text { criteria; } \\
69.4 \% \text { met } A \text { or } B \text { criteria }\end{array}$ \\
\hline Cawley $2018^{36}$ & Not Discussed & $\begin{array}{l}2005 \text { ATS/ERS guidelines of a FVC or } \\
\text { FEV , within } 0.150 \mathrm{~L} \text { or } 150 \mathrm{ml} \text { of the next } \\
\text { largest value }\end{array}$ & $87 \%$ met quality standard \\
\hline Fuller ${ }^{28}$ & EasyOne ${ }^{\circledR}$ Device $^{d}$ & $\begin{array}{l}\text { Adapted } 2005 \text { ATS/ERS criteria; three } \\
\text { tracings had to be acceptable, and } \\
\text { repeatability was desirable but not } \\
\text { required }\end{array}$ & $\begin{array}{l}\text { Completion of } 3 \text { successful tests occurred in } \\
\text { 175/185 (94.6\%) of spirometry tests; of those, } \\
99 \%(174) \text { were deemed acceptable tests after } \\
\text { review by pulmonologist }\end{array}$ \\
\hline Lei Burton ${ }^{33}$ & EasyOne ${ }^{\circledR}$ Device $^{d}$ & $\begin{array}{l}\text { Spirometer device grading system (A-D, } \\
\text { F), that corresponds to } 2005 \text { ATS/ERS } \\
\text { quality standards }\end{array}$ & $\begin{array}{l}80.7 \% \text { met } A, B \text {, or } C \text { criteria; } \\
68.5 \% \text { met } A \text { or } B \text { criteria }\end{array}$ \\
\hline
\end{tabular}

Notes: ${ }^{\mathrm{a} R J}$ and VK Bird Pty Ltd, Melbourne, Victoria, Australia. ${ }^{b}$ Welch-Allyn, Skaneateles Falls, NY USA. ' Jaeger-Toennis, Hochberg, Germany. ${ }^{\mathrm{d}}$ Ndd Medical Technologies, Zurich, Switzerland.

Abbreviations: ATS, American Thoracic Society; ERS, European Respiratory Society; FEVI, Forced Expiratory Volume in one second; FVC, Forced Vital Capacity. 
is important to note that there was not consistency in how quality was measured, given the changing parameters of the ATS/ERS guidelines over time. For studies included in this review, 66-94\% of pharmacist performed spirometry met the quality standard utilized in the study. A review of pharmacists' quality of spirometry in 2015, including many of the same studies as this review, noted that pharmacists performed quality spirometry at similar rates to other healthcare professionals. ${ }^{13}$ In one highlighted study of 13,599 patients, trained healthcare providers maintained ATS/ERS standards in 70-88\% of tests performed. ${ }^{48}$ This current review confirms that pharmacists were able to perform spirometry that met similar quality standards to other healthcare providers, but there is work to be done in assuring that all literature is reporting the same quality data. Future studies should use the most recent quality standards and report outcomes consistent with those standards, allowing for statistical analysis of the spirometry data across the literature.

\section{Complementary Pharmacist Services}

Both the GINA and GOLD practice guidelines recognize the value of pharmacists in respiratory disease management, specifically in assessing inhaler technique, providing adherence support, and educating patients about their disease. $^{1,3}$ In 2011, the American Pharmacists Association Foundation published three opportunities for pharmacists involved in the care of patients with COPD, which also translate to asthma: improving medication adherence, smoking cessation, and medication therapy management. ${ }^{49}$ These outlined areas of opportunity also appeared to be the most common services offered alongside spirometry throughout the studies included in this review. A summary of the complementary services can be found in Table 1.

Many of the pharmacist spirometry services emphasized proper inhaler technique to improve adherence and disease outcomes $(n=12) .^{12,18-21,25,30,32,35,36,39,40}$ The extent of inhaler technique counseling was not thoroughly described in all these programs. Armour et al studies cited utilizing "devicespecific checklists" to assess inhaler use, ${ }^{19-21}$ while others were less descriptive of teaching modalities. It has been established that errors in inhaler technique are associated with poorer disease control and that pharmacists can offer proper interventions and counseling to improve adherence. ${ }^{50}$ This education is well within the scope of pharmacists and spirometry results could help to measure the impact of proper inhaler use or identify patients who may need additional medication counseling.

Similar to proper inhaler use, it is reasonable to assume that pharmacists managing patients with respiratory disease would prioritize addressing smoking cessation. The review by Twigg and Wright specifically states that

Due to the relationship between smoking and the development of COPD, it is potentially inappropriate to deliver a screening service without having the expertise to deliver (or refer to) a smoking cessation service. ${ }^{14}$

Within this review, history of smoking was a common part of initial inclusion parameters for screening patients who may benefit from spirometry. Pharmacists commonly provided smoking cessation literature or counseling, with the majority of studies reporting $97-100 \%$ of patients identified as smokers receiving this service..$^{23,24,28,35,39}$ Like adherence efforts, authors noted the existence of smoking cessation interventions, but they were not described in full detail. Aspects of the services such as if pharmacotherapy was offered, or what kind of counseling was given, were unavailable. One study specifically mentioned utilizing the results of spirometry as an objective measure of a patient's lung health in providing cessation recommendations and counseling. ${ }^{28}$ A 2019 review by Westerdahl et al concluded that while

studies conducted to date have shown mixed results, there is currently limited evidence in the literature that smoking cessation counseling that includes feedback from spirometry and a demonstration of lung age promotes quit rates. ${ }^{51}$

However, a recent randomized controlled trial demonstrated that brief smoking cessation advice plus spirometry information doubled prolonged abstinence at 12 months compared to brief advice alone. ${ }^{52}$ While the data supporting spirometry in smoking cessation is not yet well established, this could be an opportunity for pharmacists to include information such as lung age provided by spirometry, as part of their smoking cessation education services.

The extent of pharmacist involvement in medication management varied across studies. In some studies, pharmacists would review medication lists and provide evidence-based recommendations for altering medication therapy. The strongest evidence of these interventions came from studies of pharmacists in outpatient clinics, where diagnostic spirometry results were utilized. $^{35,36,38,39,41}$ In these studies, pharmacists 
recommended medication changes in $46-69 \%$ of patients based on evidence-based guidelines. ${ }^{36,38,41}$ These changes included adding therapy (55\%), discontinuing therapy (26\%), and/or adjusting doses of medications $(12 \%) .^{35,36}$ Follow-up data on these recommendations was limited. However, Mueller et al reported $87 \%$ of pharmacists' recommendations were accepted by providers, suggesting they value pharmacist input. ${ }^{38}$ Medication management services offered in conjunction with spirometry may increase patient engagement and improve clinical and humanistic outcomes. Simpson et al compared an asthma service with and without spirometry and found that patients that had spirometry were more likely to see their PCP when referred by the pharmacist $(75 \%$ compared to $33 \%) .{ }^{30}$ Two cluster randomized controlled trials in Australia demonstrated that a pharmacist asthma management program that includes spirometry positively impacted asthma severity/control, inhaler technique, action plan ownership, asthma-related quality of life, and medication adherence. ${ }^{19,21}$ It is difficult to discern if these outcomes should be attributed to spirometry or the medication management and patient education components of the service. ${ }^{19,21}$ Future studies comparing the effectiveness of pharmacist respiratory management services with and without spirometry would provide additional information on the utility of including spirometry in pharmacy-based medication management services.

Overall, there was a lack of details for these other services, their depth, and outcomes. The dearth of outcomes data could be explained by the difference in settings for the services reviewed: community versus outpatient clinic practice. Outpatient clinic practices had access to the EMR, which facilitated communication between pharmacists and providers and allowed for researchers to access additional data that studies in community pharmacy settings did not have access to. Future studies, especially in community pharmacy settings, should seek to streamline communication and ensure access to outcomes data relevant to the services provided.

Lastly, a benefit of spirometry may lie in its ability to attract patients and draw attention to other services. Allan et al revealed pharmacists believed spirometry services served to increase awareness of the pharmacy's other services. ${ }^{18}$ Similar to other point of care tests utilized in pharmacy practice, like blood pressure, spirometry could offer an opportunity for pharmacists to collect objective patient information as a part of a comprehensive, evidence-based patient care service. Spirometry services may add the most value when they are complementary and offered in conjunction with other services that leverage pharmacist expertise, like smoking cessation, disease-state and medication education, and collaborative medication management.

\section{Pharmacist Perspectives on Spirometry}

Six studies specifically sought to gather feedback from pharmacists offering spirometry services, all of which were in the community pharmacy setting. Survey methods were used in four studies, with response rates varying from $58-100 \%{ }^{18,26-28}$ Three studies utilized focus groups and/ or interviews with participating pharmacists, with sample sizes of $4,{ }^{29} 15,{ }^{27}$ and $32 .{ }^{25}$ Some papers had stronger qualitative research methodology, ${ }^{25,27}$ while others were designed for the purposes of evaluating the program and did not employ rigorous research methods. ${ }^{18,29}$ For most studies included in this paper, pharmacists opted in to providing the spirometry service so pharmacist responses may be biased and not reflective of the general pharmacist population.

Several studies found that pharmacists were confident in their ability to provide spirometry services following comprehensive training, ${ }^{28,29}$ including identifying patients at risk, conducting the test, interpreting results, and referring to primary care providers. ${ }^{26}$ Fuller et al found that pharmacists with lower comfort had performed fewer spirometries $^{28}$ and Allan et al described the importance of initiating the service soon after training to enhance pharmacist confidence. ${ }^{18}$

Community pharmacists commonly cited patient recruitment as a challenge and some pharmacists felt that they needed more training or support in how to approach patients for this clinical service. ${ }^{25,27,28}$ Pharmacists identified patients' lack of awareness of COPD as a barrier to recruitment. ${ }^{27} \mathrm{~A}$ known facilitator to patient recruitment is marketing and promotion of the pharmacy service. When the services were well advertised in local media and through screening days supported by the Australian Lung Foundation, pharmacists were inundated with patients requesting spirometry. ${ }^{18}$

Challenges with pharmacist availability were commonly cited by the community pharmacists as barriers to service implementation and success. Pharmacists reported trying to schedule patients when two pharmacists were on duty so the service could be provided uninterrupted. ${ }^{25,29}$ Some pharmacies chose to do lung screenings days with 
a pharmacist dedicated to spirometry so that the service did not interrupt normal workflow of the pharmacy. ${ }^{27}$ Good staff support is a facilitator to implementation. Pharmacists reported engaging technicians in identifying target patients, recruiting patients and having patients fill out the questionnaire. ${ }^{27}$ Where pharmacists did not include technicians in the study, they reported envisioning similar roles for support staff if the service were to be continued. ${ }^{18,29}$

Pharmacists found the service to be professionally rewarding and most reported an interest in continuing the service. ${ }^{18,25,27}$ Suggested changes for the service involved simplifying documentation, ${ }^{18,27}$ integrating spirometry with other health screening services, ${ }^{27}$ addressing time constraints and scheduling issues, ${ }^{25}$ and increasing demand through advertisements and public awareness campaigns. ${ }^{27,29}$ For many, remuneration for the service was necessary to continue offering spirometry in the future. $^{18,25,27}$

\section{Provider Perspectives}

One of the most challenging aspects noted in many of the publications was the communication and acceptance of pharmacists' recommendations to PCPs. Physicians and other primary care providers, like the public, may not be aware of the capabilities and training of a pharmacist.

Tilly-Gratton et al examined Quebec physicians' agreement on expanding the role of pharmacists in managing asthma. The survey generated a $56 \%$ response rate from 420 physicians specializing in family medicine, pediatrics, or emergency medicine. Physicians were asked to rank agreement with the statement

I am comfortable with the professional activities of pharmacists enabling them to offer pulmonary function tests (e.g., spirometry) in the pharmacy to monitor my patient's therapy.

Only $49 \%$ of the physicians agreed by scoring a 4 or 5 on the 6-point Likert scale that pharmacists should offer spirometry for monitoring patients with asthma. The findings of this question should not be surprising. Many physicians may be concerned about the training of the pharmacists and the accuracy of the spirometer used. Other physicians may want to be more involved with the monitoring of their asthma patients and do not feel additional services are needed. This last statement is supported by the authors' findings where pediatricians and family medicine doctors were more likely to disagree with pharmacists monitoring patients with spirometry compared to emergency department doctors agreeing with pharmacists helping to monitor asthma patients. One limitation noted by the authors was the survey was conducted prior to the passage of a law expanding the pharmacist professional activities, so physicians may not have experience working with pharmacists in these roles. ${ }^{53}$

Cawley et al provided physician perspectives in a narrative review of successful pharmacist spirometry services at three different primary care settings. ${ }^{12}$ Spirometry services provided by pharmacists in primary care settings enhanced interprofessional education for family medicine residents and medical students, improved testing convenience for patients and provided prompt results for physicians. ${ }^{12}$

Future research to gather primary care provider's perspectives on pharmacist-provided spirometry are warranted given the lack of data that is available. These studies could uncover important perspectives that could influence the design and implementation of spirometry services.

\section{Patient Perspectives}

Limited information is available on the patients' perspectives of pharmacists providing spirometry. A few studies gathered patient feedback and indicated the service to be helpful and convenient. In one study, patients were asked about their satisfaction with the spirometry service and were very satisfied (4.64 standard deviation 0.5 , on a scale $0-5$, where 5 is very satisfied) and willing to pay for spirometry services that were provided by pharmacists working in Australian independent pharmacies. ${ }^{18}$ Whereas, patients in the United States were more motivated to attempt quitting smoking after completing free testing in a community pharmacy setting. ${ }^{28}$ However, patients were challenging to reach by phone and email, post-screening. The numbers of patients surveyed were minimal and bias was present with patients being selected to complete surveys and interviews. Most of the analysis about patient satisfaction came from the pharmacists providing the spirometry service. Overall, community pharmacists indicated patient engagement in testing and reviewing the results, and patient appreciation of free and convenient testing. ${ }^{25,27,29}$ More analysis of the patient experience with pharmacist provided spirometry in community and other settings is warranted. 


\section{Limitations}

Our scoping review has some limitations. Despite inclusion of papers describing pharmacist services in six countries, the search may have been limited by the inclusion criteria for records available in English. This scoping review utilized a modified approach in developing the search strategy that deviates from the recommendations for a scoping review from the Joanna Briggs Institute. ${ }^{16}$ While one author did conduct an initial limited search and discuss the findings with the other authors to determine additional search criteria, a formal analysis of text words in the titles and abstracts and index terms was not done. This may have resulted in some useful terms being left out of our search and some articles may have been missed as a result. Another limitation is that the authors used PubMed and EMBASE databases for the search, which results in an approximate yield of $92 \%$, meaning some articles may have been missed. ${ }^{54}$ Including additional databases, such as Google Scholar and Web of Science may have resulted in an additional 1-2 articles being identified for inclusion. ${ }^{54}$ Given that there were many common themes across the articles that were identified, the authors did not feel that an additional 1-2 articles would significantly alter the findings of this review.

\section{Conclusion}

Studies of pharmacist provided spirometry have been conducted around the world in community pharmacies and clinic-based practices. While community pharmacists may increase access to spirometry screening services for patients, the lack of communication with PCPs and lack of remuneration for spirometry in this setting are barriers that need to be overcome to optimize the utility of spirometry services in the community pharmacy setting. Clinic-based spirometry services provided by pharmacists may increase patient access to diagnostic testing and PCP access to results, as providers may be more likely to refer patients when a service exists in their practice and patients may be more likely to complete spirometry when it is conveniently located in the PCP's office. Clinic-based services were often interprofessional and collaborative, allowing a patient to receive the test, test results, diagnosis, and medication changes all in one visit. Pharmacists were able to secure payment in clinic settings, making spirometry a potential area of future growth for sustainable pharmacist services.
Spirometry services were often offered with other clinical pharmacy services such as smoking cessation, inhaler technique assessment and adherence support, and medication management. Collaborative practice agreements for chronic disease management for pulmonary conditions and tobacco use are opportunities for pharmacists to leverage their expertise and spirometry could be a complementary service that supports those services.

This review confirmed that pharmacists can meet quality standards for spirometry at rates similar to other healthcare providers. Following comprehensive training, pharmacists felt confident in their ability to perform spirometry and found the service to be professionally rewarding. Data around provider and patient perspectives is limited and should be further investigated to determine if providers and patients would find value in and be willing collaborators for pharmacist provided spirometry services.

Spirometry testing provides an opportunity for pharmacists to improve evidence-based practice for screening and diagnosis of lung conditions and can provide a pipeline of patients for chronic disease management services under consult agreements.

\section{Disclosure}

The authors report no conflicts of interest in this work.

\section{References}

1. Global Initiative for Chronic Obstructive Lung Disease. Global strategy for the diagnosis, management, and prevention of chronic obstructive pulmonary disease 2021 report; 2020. Available from: https:// goldcopd.org/2021-gold-reports/. Accessed July 30, 2021.

2. Vos T, Lim SS, Abbafati C, et al. Global burden of 369 diseases and injuries in 204 countries and territories, 1990-2019: a systematic analysis for the Global Burden of Disease Study 2019. Lancet. 2020;396(10258):1204-1222. doi:10.1016/S0140-6736(20)30925-9

3. Global Initiative for Asthma. Global strategy for asthma management and prevention 2020; 2020. Available from: www.ginasthma.org. Accessed July 30, 2021.

4. Ruppel GL, Carlin BW, Hart M, Doherty DE. Office spirometry in primary care for the diagnosis and management of COPD: national lung health education program update. Respir Care. 2018;63 (2):242-252. doi:10.4187/respcare.05710

5. Graham BL, Steenbruggen I, Miller MR, et al. Standardization of spirometry 2019 update. An official American Thoracic Society and European Respiratory Society technical statement. Am J Respir Crit Care Med. 2019;200(8):e70-e88. doi:10.1164/rccm.201908-1590ST

6. Radin A, Cote C. Primary care of the patient with chronic obstructive pulmonary disease-part 1: frontline prevention and early diagnosis. $\mathrm{Am}$ $J$ Med. 2008;121(7):S3-S12. doi:10.1016/j.amjmed.2008.04.002

7. Yu WC, Fu SN, Tai EL, et al. Spirometry is underused in the diagnosis and monitoring of patients with chronic obstructive pulmonary disease (COPD). Int J Chron Obstruct Pulmon Dis. 2013;8:389-395. doi:10.2147/COPD.S48659 
8. Tsuyuki RT, Sin DD, Sharpe HM, et al. Management of asthma among community-based primary care physicians. J Asthma. 2005;42(3):163-167. doi:10.1081/JAS-54615

9. Dombkowski KJ, Hassan F, Wasilevich EA, Clark SJ. Spirometry use among pediatric primary care physicians. Pediatrics. 2010;126 (4):682-687. doi:10.1542/peds.2010-0362

10. Glasgow N. Systems for the management of respiratory disease in primary care - an international series: Australia. Prim Care Respir J. 2008;17(1):19-25. doi:10.3132/pcrj.2008.00015

11. Saad N, Sedeno M, Metz K, Bourbeau J. Early COPD diagnosis in family medicine practice: how to implement spirometry? Int J Family Med. 2014;2014:1-6. doi:10.1155/2014/962901

12. Cawley MJ, Moon J, Reinhold J, Willey VJ, Warning Ii WJ. Spirometry: tool for pharmacy practitioners to expand direct patient care services. J Am Pharm Assoc. 2013;53(3):307-315. doi:10.1331/ JAPhA.2013.12134

13. Cawley MJ, Warning WJ. Pharmacists performing quality spirometry testing: an evidence based review. Int J Clin Pharm. 2015;37 (5):726-733. doi:10.1007/s11096-015-0160-х

14. Twigg MJ, Wright DJ. Community pharmacy COPD services: what do researchers and policy makers need to know? Integr Pharm Res Pract. 2017;6:53-59. doi:10.2147/IPRP.S105279

15. Tricco AC, Lillie E, Zarin W, et al. PRISMA extension for scoping reviews (PRISMA-ScR): checklist and explanation. Ann Intern Med. 2018;169(7):467-473. doi:10.7326/M18-0850

16. Peters MDJ, Godfrey CM, Khalil H, McInerney P, Parker D, Soares CB. Guidance for conducting systematic scoping reviews. Int $J$ Evid Based Healthc. 2015;13(3):141-146. doi:10.1097/ XEB.0000000000000050

17. Roy Rosenzweig Center for History and New Media at George Mason University. Zotero; 2021. Available from: https://www. zotero.org/. Accessed July 30, 2021.

18. Allan H, Diamandis S, Saini B, Marshall D, Gavagna G, PetersonClark G. A collaborative screening, referral and management process to improve health outcomes in Chronic Obstructive Pulmononary Disease (COPD). Australian Government Department of Health and Ageing; 2021. Available from: https://6cpa.com.au/resources/fourthagreement/a-collaborative-screening-referral-and-managementprocess-to-improve-health-outcomes-in-chronic-obstructivepulmonary-disease-copd/. Accessed March 5, 2021.

19. Armour C, Bosnic-Anticevich S, Brillant M, et al. Pharmacy Asthma Care Program (PACP) improves outcomes for patients in the community. Thorax. 2007;62(6):496-502. doi:10.1136/ thx.2006.064709

20. Armour CL, LeMay K, Saini B, et al. Using the community pharmacy to identify patients at risk of poor asthma control and factors which contribute to this poor control. J Asthma. 2011;48(9):914-922. doi:10.3109/02770903.2011.615431

21. Armour CL, Reddel HK, LeMay KS, et al. Feasibility and effectiveness of an evidence-based asthma service in Australian community pharmacies: a pragmatic cluster randomized trial. $J$ Asthma. 2013;50 (3):302-309. doi:10.3109/02770903.2012.754463

22. Burton MA, Burton DL, Simpson MD, Gissing PM, Bowman SL. Respiratory function testing: the impact of respiratory scientists on the training and support of primary health care providers. Respirology. 2004;9(2):260-264. doi:10.1111/j.14401843.2004.00563.x

23. Castillo D, Guayta R, Giner J, et al. COPD case finding by spirometry in high-risk customers of urban community pharmacies: a pilot study. Respir Med. 2009;103(6):839-845. doi:10.1016/j. rmed.2008.12.022

24. Castillo D, Burgos F, Guayta R, et al. Airflow obstruction case finding in community-pharmacies: a novel strategy to reduce COPD underdiagnosis. Respir Med. 2015;109(4):475-482. doi:10.1016/j. rmed.2015.02.009
25. Emmerton LM, Smith L, LeMay KS, et al. Experiences of community pharmacists involved in the delivery of a specialist asthma service in Australia. BMC Health Serv Res. 2012;12:164. doi: 10.1186/1472-6963-12-164

26. Fathima M, Saini B, Foster JM, Armour CL. Community pharmacy-based case finding for COPD in urban and rural settings is feasible and effective. Int $J$ Chron Obstruct Pulmon Dis. 2017;12:2753-2761. doi:10.2147/COPD.S145073

27. Fathima M, Saini B, Foster JM, Armour CL. A mixed methods analysis of community pharmacists' perspectives on delivering COPD screening service to guide future implementation. Res Social Adm Pharm. 2019;15 (6):662-672. doi:10.1016/j.sapharm.2018.08.007

28. Fuller L, Conrad WF, Heaton PC, Panos R, Eschenbacher W, Frede SM. Pharmacist-managed chronic obstructive pulmonary disease screening in a community setting. $J$ Am Pharm Assoc (2003). 2012;52(5):e59-e66. doi:10.1331/JAPhA.2012.11100

29. Krska J, Corlett S. Evaluation of NHS Health Checks provided by community pharmacists with the addition of spirometry. 2014. Available from: https://www.researchgate.net/profile/Janet-Krska/ publication/272453266_Evaluation_of_NHS_Health_Checks_with_ the_addition_of_spiromtery_testing_Lewisham_CCG/links/

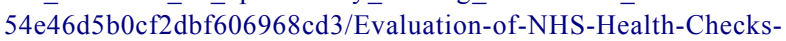
with-the-addition-of-spiromtery-testing-Lewisham-CCG.pdf. Accessed December 17, 2020.

30. Simpson MD, Burton DL, Burton MA, Gissing PM, Bowman SL. Pharmaceutical care: impact on asthma medication use. J Pharm Pract Res. 2004;34(1):26-29. doi:10.1002/jppr20043 4126

31. Solidoro P, Braido F, Baratta F, et al. FEV6 assessment in spirometric abnormalities screening: the first population-based study in Italian pharmacies. Panminerva Med. 2013;55(1):87-92.

32. Wright D, Twigg M, Thornley T. Chronic obstructive pulmonary disease case finding by community pharmacists: a potential cost-effective public health intervention. Int $J$ Pharm Pract. 2015;23(1):83-85. doi:10.1111/ijpp.12161

33. Lei Burton D, LeMay KS, Saini B, et al. The reliability and utility of spirometry performed on people with asthma in community pharmacies. $J$ Asthma. 2015;52(9):913-919. doi:10.3109/ 02770903.2015.1004684

34. Siu AL, Bibbins-Domingo K, Grossman DC, et al.; US Preventive Services Task Force (USPSTF). Screening for chronic obstructive pulmonary disease: US Preventive Services Task Force recommendation statement. JAMA. 2016;315(13):1372-1377. doi:10.1001/ jama.2016.2638.

35. Cawley MJ, Pacitti R, Warning W. Assessment of a pharmacist-driven point-of-care spirometry clinic within a primary care physicians office. Pharm Pract (Granada). 2011;9(4):221-227. doi:10.4321/s1886-36552011000400007

36. Cawley MJ, Warning WJ. Impact of a pharmacist-driven spirometry clinic service within a community family health center: a 5 -year retrospective review. $J$ Res Pharm Pract. 2018;7(2):88-94. doi:10.4103/jrpp.JRPP_17_101

37. Licskai CJ, Sands TW, Paolatto L, Nicoletti I, Ferrone M. Spirometry in primary care: an analysis of spirometery test quality in a regional primary care asthma program. Can Respir J. 2012;19(4):249-254. doi: $10.1155 / 2012 / 653084$

38. Mueller LA, Valentino AS, Clark AD, Li J. Impact of a pharmacist-provided spirometry service on access to results in a primary care setting. J Prim Care Commun Health. 2018;9:2150132718759213. doi:10.1177/2150132718759213

39. Whitner JB, Mueller LA, Valentino AS. Pharmacist-driven spirometry screening to target high-risk patients in a primary care setting. J Prim Care Commun Health. 2019;10:2150132719889715. doi: $10.1177 / 2150132719889715$ 
40. Willey VJ, Simon S, Akkineni S, et al. Pharmacist-led services to patients with respiratory diseases: feasible from a quality and reimbursement perspective? Value Health. 2013;16(3):A198. doi:10.1016/ j.jval.2013.03.998

41. Mann RP, Zaiken K. Management of chronic obstructive pulmonary disease by pharmacists in an internal medicine department. Am $J$ Health Syst Pharm. 2009;66(10):890, 892-893. doi:10.2146/ ajhp080258

42. Cooper B, Steenbruggen I, Mitchell S, et al. HERMES spirometry: the European spirometry driving licence. Breathe. 2011;7 (3):258-275. doi:10.1183/20734735.026310

43. Swanney MP, O’Dea CA, Ingram ER, Rodwell LT, Borg BM. Spirometry training courses: content, delivery and assessment a position statement from the Australian and New Zealand Society of Respiratory Science. Respirology. 2017;22(7):1430-1435. doi:10.1111/resp. 13133

44. American Lung Association. Spirometry training; 2021. Available from: https:/www.lung.org/professional-education/trainingcertification/spirometry-training. Accessed May 6, 2021.

45. Rogers K, Martin M, Clark K. National Institute for Occupational Safety and Health Spirometry Training Program. US Department of Health and Human Services, Centers for Disease Control and Prevention, National Institute for Occupational Safety and Health, DHHS (NIOSH) Publication No 2019-110. 2019. doi:10.26616/ NIOSHPUB2019110.

46. American Thoracic Society. Standardization of spirometry, 1994 update. Am J Respir Crit Care Med. 1995;152(3):1107-1136. doi:10.1164/ajrccm.152.3.7663792.

47. Miller MR, Hankinson J, Brusasco V, et al. Standardisation of spirometry. Eur Respir J. 2005;26(2):319-338. doi:10.1183/ 09031936.05 .00034805
48. Enright PL, Skloot GS, Cox-Ganser JM, Udasin IG, Herbert R. Quality of spirometry performed by 13,599 participants in the world trade center worker and volunteer medical screening program. Respir Care. 2010;55(3):303-309.

49. Bluml BM; American Pharmacists Association Foundation null. White paper on expanding the role of pharmacists in chronic obstructive pulmonary disease: American Pharmacists Association Foundation. J Am Pharm Assoc. 2011;51(2):203-211. doi:10.1331/ JAPhA.2011.11513

50. Hudd TR. Emerging role of pharmacists in managing patients with chronic obstructive pulmonary disease. Am J Health Syst Pharm. 2020;77(19):1625-1630. doi:10.1093/ajhp/zxaa216

51. Westerdahl E, Engman KO, Arne M, Larsson M. Spirometry to increase smoking cessation rate: a systematic review. Tob Induc Dis. 2019;17:31. doi:10.18332/tid/106090

52. Martin-Lujan F, Basora-Gallisa J, Villalobos F, et al. Effectiveness of a motivational intervention based on spirometry results to achieve smoking cessation in primary healthcare patients: randomised, parallel, controlled multicentre study. J Epidemiol Commun Health. 2021. doi:10.1136/jech-2020-216219

53. Tilly-Gratton A, Lamontagne A, Blais L, et al. Physician agreement regarding the expansion of pharmacist professional activities in the management of patients with asthma. Int J Pharm Pract. 2017;25 (5):335-342. doi:10.1111/ijpp. 12320

54. Bramer WM, Rethlefsen ML, Kleijnen J, Franco OH. Optimal database combinations for literature searches in systematic reviews: a prospective exploratory study. Syst Rev. 2017;6(1):245. doi:10.1186/s13643-017-0644-y
Integrated Pharmacy Research and Practice

\section{Publish your work in this journal}

Integrated Pharmacy Research and Practice is an international, peerreviewed, open access, online journal, publishing original research, reports, reviews and commentaries on all areas of academic and professional pharmacy practice. This journal aims to represent the academic output of pharmacists and pharmacy practice with particular focus on integrated care. All papers are carefully peer reviewed to ensure the highest standards as well as ensuring that we are informing and stimulating pharmaceutical professionals. The manuscript management system is completely online and includes a very quick and fair peer-review system, which is all easy to use. Visit http://www.dovepress.com/testimonials.php to read real quotes from published authors. 